IP Periodica Polytechnica Electrical Engineering and Computer Science

61(1), pp. 62-68, 2017

DOI: 10.3311/PPee.10073

Creative Commons Attribution (i)

RESEARCH ARTICLE

\section{Decreasing Reserve Requirements of Wind Power Plants by a Redesigned Obligatory Electricity Purchase and Tariff System}

\author{
Bálint Hartmann ${ }^{1 *}$
}

Received 27 September 2016; accepted 14 December 2016

\begin{abstract}
Since the widespread utilisation of wind power has begun in the early 2000 's, European countries are continuously working on the legislative environment of this renewable energy source. This has led to a wide variety of different support schemes and tariff systems. Experts agree that the Hungarian legislation system did not reach its goal. On one hand, scheduling accuracy of wind turbines is still far below international standards, and introduction of the penalty tariff was not an effective solution to reverse the process. The aim of the author is to solve this twofold problem with the redesign of the current obligatory electricity purchase and scheduling system, while taking into consideration new regulations of the European Union. The proposed system is also expected to allow the transmission system operator to decrease the amount of control reserves.
\end{abstract}

\section{Keywords}

wind energy, power system planning, power system economics

${ }^{1}$ Department of Electric Power Engineering, Faculty of Electrical Engineering and Informatics, Budapest University of Techology and Economics, H-1111 Budapest, Egry J. u. 18., Hungary

*Corresponding author, e-mail: hartmann.balint@vet.bme.hu

\section{Introduction}

The continuously increasing penetration of intermittent energy sources (mainly wind and solar photovoltaics) has led to growing concerns about the possible limitations of penetration levels. Integration issues are among the most widely discussed topics in the literature; numerous studies are performed to assess the impact of variable renewable energy sources on reliability, efficiency and the quality of supply, in general. An often emphasised issue is that integration increases the amount of balancing reserves that has to be kept in the power systems, and there are also misconceptions that variable renewable are exempted from balancing responsibilities. This makes it inevitable to focus on the best practices of exposing these producers to these responsibilities and their participation in the market. However, determining the uncertainty posed by the integration of renewable sources is not a straightforward process. Experts also share different standpoints on how to solve the balancing issues; by serving the increased reserve needs or by trying to decrease them are both seen as viable solutions. In present paper the integration of wind power is selected as an archetype.

The first solution is based on the idea of modifying current method of reserve planning, by leaving deterministic methods for stochastic methods that are able to take into consideration the scheduling error of wind power plants. Such methods are not new to power system experts, they were introduced as early as in [1]. They are based on a statistical approach and offer to handle the scheduling error of wind power plants as a random variable. The necessary amount of reserves for a pre-set level of uncertainty will be determined by the area under the curve of the probability density function ( $p d f)$ of this random variable then. A more detailed examination of the issue is given in [2], where various reserve planning methods are compared, including both deterministic and stochastic ones. The authors summarize that former ones tend to overestimate the amount of necessary balancing reserves, thus increasing the cost of operation.

A stochastic planning method is presented in [3], which handles the loss of generation and the scheduling errors (of load and generation) as random variables. This enables the construction of a single $p d f$ to determine necessary reserves. The authors 
also recommend the use of short horizon forecasts to decrease sensitivity issues; this need can be met e.g. by intraday scheduling. Experiences of Germany show a similar approach in [4]. According to the paper, the use of stochastic planning methods may decrease operation costs by one third. The example of Germany is cited, where the significant increase in the accuracy of wind power forecasts resulted in saving 15 billion EUR.

The second, often used solution is to use financial motivation to decrease balancing reserve needs of variable renewable energy sources. All such systems can be classified here that are penalising scheduling errors or are motivating more accurate scheduling. Focusing on the 28 member states of the European Union (EU), penalties were introduced in far less places than incentives, like feed-in tariffs or green certificates. (It is also worth noting that most of these countries do not prescribe obligatory purchase of electricity produced from renewable sources.) [5] At the same time, in at least 14 member states, where the share of wind power in annual generation is above $2-3 \%$, generators are responsible for balancing in some form. The range of balancing costs for wind power plants are between 2 and 3 EUR/MWh on average, with the exception of Bulgaria (10-24 EUR/MWh), Romania (8-10 EUR/ MWh), Austria and Spain (both around 1 EUR/MWh). [6]

The literature also widely discusses proposals concerning new tariff structures, which could create a fairer burden sharing between the power plants. Five different schedule planning methods (e.g. stochastic and moving average) are compared in [7]. The effectiveness of them is shown, while the authors also detail necessary changes to implement them in power system operations. In [8] dataset of Chinese wind farms is examined, to create a new method for penalizing scheduling errors. The authors take a similar approach as in present paper, as specific revenue of wind power plants is calculated based on their scheduling accuracy. The results indicate that the proposed method is capable of mitigating the errors of the schedule; however these findings are not used to decrease the necessary amount of balancing reserves.

The case of The Netherlands is useful to mention as well, due to its contradictions. As the authors of [9] highlight, wind power plants intentionally present inaccurate values during the intraday scheduling process, so that they will get involved in the balancing energy market. Penalties (balancing costs) are determined based on market prices, which can be well estimated on a few hour horizon.

The previously shown trends represent an issue that is yet to be solved in Hungary. The root mean square (RMS) error of Hungarian wind power plant schedules is $10.53 \%$ compared to the nominal capacity of the units, which is significantly bigger than similar values of other countries. [10-14] The Hungarian Energy Office (the national regulator) has also made it clear that the current scheduling and tariff system is not capable of creating the lacking motivation for wind power plant operators, to improve their scheduling accuracy. [15]
The Hungarian Act LXXXVI of 2007, the new act on electricity, together with the Governmental Decrees 273/2007 and $389 / 2007$ contain current regulatory framework for renewable energy sources. Since the introduction of these, scheduling for distributed generator units (combined heat and power units, wind, solar, etc.) is obligatory. All producers have to present a schedule of their production with 15-minute resolution, one day prior. A penalty tariff is paid if production exceeds certain range $( \pm 5 \%$ in case of regular and $\pm 50 \%$ in case of wind power plants) of the schedule, the amount of which is $5 \mathrm{HUF} /$ kWh ( 16.67 EUR/MWh) for every kWh outside the permitted range of the schedule. The feed-in tariffs in the obligatory electricity purchase system were $35.91 \mathrm{HUF} / \mathrm{kWh}(\sim 120 \mathrm{EUR} /$ MWh), $32.14 \mathrm{HUF} / \mathrm{kWh}$ ( 107 EUR/MWh), and 13.11 HUF/ kWh ( 44 EUR/MWh) for peak, valley and deep-valley hours respectively, in 2015. These prices are revised each year by the regulator, and modified if necessary. 16 hours are considered as peak period on weekdays, while valley and deep-valley lasts for 4.5 and 3.5 hours. On non working days only two categories are distinguished, a valley of 20.5 hours and a deep-valley of 3.5 hours. Exact timing of these periods also depends on winter and summer times. For the following calculations, the author has assumed that the probability of a wind power plant producing electricity is independent of the time of the day, a fictive feed-in tariff can be calculated, using the weighted average of the above described periods. This 24 hour tariff is $31.12 \mathrm{HUF} /$ kWh $(\sim 104$ EUR/MWh) and was used for further calculations. This can be compared to selected feed-in tariffs of other EU countries, listed in Table 1, showing that Hungarian tariffs are among the highest.

Table 1 Indicative comparison of feed-in tariffs in EU countries, according to RES LEGAL Europe (onshore units above $2 \mathrm{MW}$, eligible for new capacities)

\begin{tabular}{llll}
\hline Country & $\begin{array}{l}\text { Feed-in tariff } \\
{[\mathrm{cEUR} / \mathrm{kWh}]}\end{array}$ & Country & $\begin{array}{l}\text { Feed-in tariff } \\
{[\mathrm{cEUR} / \mathrm{kWh}]}\end{array}$ \\
\hline Austria & 9.45 & Lithuania & 6.4 \\
Bulgaria & 4.9 & Luxembourg & 9.2 \\
Czech Republic & 7.3 & Portugal & $7.4-7.5$ \\
France & 8.2 & Slovakia & 7.03 \\
Germany & $4.95-8.9$ & Slovenia & 9.538 \\
Greece & 10.5 & Switzerland & 0.179 \\
Hungary & $4.4-12$ & United Kingdom & 3.9 \\
Ireland & 7.2 & & \\
\hline
\end{tabular}

While aiming to provide a solution for the controversies of the Hungarian scheduling and tariff system, newly introduced regulations also had to be considered. Namely, the new "Guidelines on State aid for environmental protection and energy 2014-2020" [16] communication of the European Commission has also made necessary to change many of current legislations and procedures. Citing paragraph (124), 
beneficiaries of aid for electricity from renewable sources are expected to sell their electricity directly in the market and are subject to market obligations, where aid is granted as a premium in addition to the market price. According to paragraph (128), in the absence of a competitive bidding process, the aid per unit of energy shall not exceed the difference between the total levelized costs of producing energy from the particular technology in question and the market price of the form of energy concerned.

Trying to solve the twofold problem, the author proposes a new obligatory electricity purchase and tariff system, which allows the TSO to decrease the amount of control reserves required by wind power plants. Section 2 presents a traditional method for planning the amount of necessary balancing reserves; this method will be used for measuring the efficiency of the redesigned system, detailed in Section 3. Section 3 shows the main results of the research, while conclusions are drawn in Section 4.

\section{Methodology}

\subsection{Planning the amount of balancing reserves}

Inside the European synchronous system, the amount of reserves is determined by the ENTSO-E Operation Handbook. [17] Within the UCTE synchronous area, the control actions and the reserves are organised in a hierarchical structure with control areas, control blocks and the synchronous are with two co-ordination centers. Control actions are performed in different successive steps, each with different characteristics and qualities, and all depending on each other. Primary control allows a balance to be re-established at a system frequency other than the frequency setpoint value, in response to a sudden imbalance of generation and consumption. The function of secondary control is to keep or to restore the power balance in each control area or block and, consequently, to keep or to restore the system frequency to its setpoint value of $50 \mathrm{~Hz}$ and the power interchanges with adjacent control areas to their scheduled values, thus ensuring that the full reserve of primary control power activated will be made available again. The size of the secondary control reserve that is required typically depends on the size of typical load variations, schedule changes and generating units. A recommended minimum reserve is given by ENTSO-E. The rate of change in the power output of generators used for secondary control must in total be sufficient for secondary control purposes. Typically for oil- or gas-fired power stations, the rate is of the order of $8 \%$ of rated capacity per minute. In case of hydro plants, the range is between 1.5$2.5 \%$, while in coal-fired plants the range is from 1 to $4 \%$.

In majority of the cases, TSOs measure production of each larger power plant (or at least each balancing group) with high resolution through the SCADA system. To determine the amount of necessary control reserves, the sum of these results is used. In some cases, however, information on each plant may be utilized, as presented in the following.
Scheduling of production in the Hungarian Power System is organized on 15 minute basis, no exception for the wind power plants. These schedules are logged by the TSO, and must be published online. (Schedules are only published in a total, balancing zone wide aggregated term.) Actual production data is also measured and stored. Using these data, scheduling error of each power plant can be calculated for every 15 minute period, as follows:

$$
P_{\text {error }_{i}}=P_{\text {production }_{i}}-P_{\text {schedule }_{i}}
$$

If this error is handled as a random variable, $p d f$ of each unit can be calculated:

$$
f\left(P_{\text {errori }}\right)
$$

Typical $p d f$ of the scheduling error is shown on Fig. 1. It can be seen that the median of the $p d f$ is negative, which refers to overestimating the production.

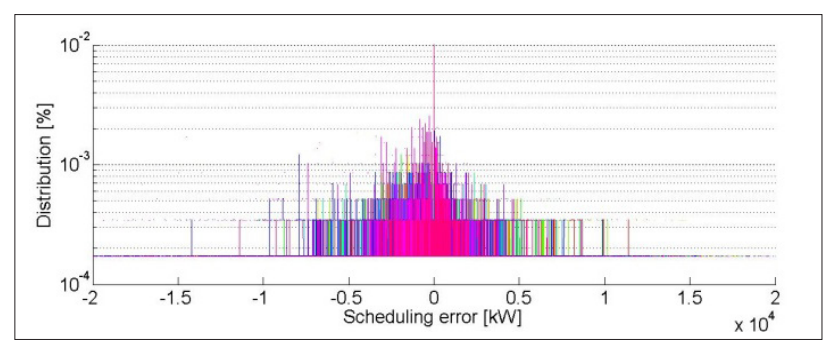

Fig. 1 Scheduling error of examined wind farms

When selecting the resolution of the $p d f$, two restrictions must be considered. If the resolution is too high, computation time increases in return for an increased accuracy. If the resolution is lower, calculations are faster, but results may be rough. As it has been emphasized, regarding the aspect of the TSO, the data carrying the most information are the sum of scheduling errors.

$$
\mathrm{P}_{\text {sum error }}=\sum_{\mathrm{n}} \mathrm{P}_{\text {error }}
$$

where $n$ is the number of independent schedulers (usually balancing groups).

The author utilizes that $p d f$ of the sum of two random variables that are independent and both have continuous distribution, can be calculated as the convolution of these distributions:

$$
\mathrm{f}(\xi+\eta)=\mathrm{f}(\xi) * \mathrm{f}(\eta)
$$

Since the operation can be performed multiple times, a single $p d f$ can characterize the scheduling error of all power plants.

$$
\mathrm{f}\left(\mathrm{P}_{\text {sum error }}\right)=\mathrm{f}\left(\mathrm{P}_{\text {error }_{1}}\right) * \mathrm{f}\left(\mathrm{P}_{\text {error }_{2}}\right) * \ldots * \mathrm{f}\left(\mathrm{P}_{\text {error }_{\mathrm{n}}}\right)
$$

The more $p d f s$ are available to perform the convolution, the "smoother" will be the result. This resulting $p d f$ ( $f$ (Psum error) ) can be used to estimate the scheduling error with a given level of uncertainty. Thus it is the responsibility of the 
TSO to decide on the level of uncertainty that it is willing to take, which is usually done based on available information and operational experience. The convolution of the $p d f s$ of Fig. 1 are shown on Fig. 2.

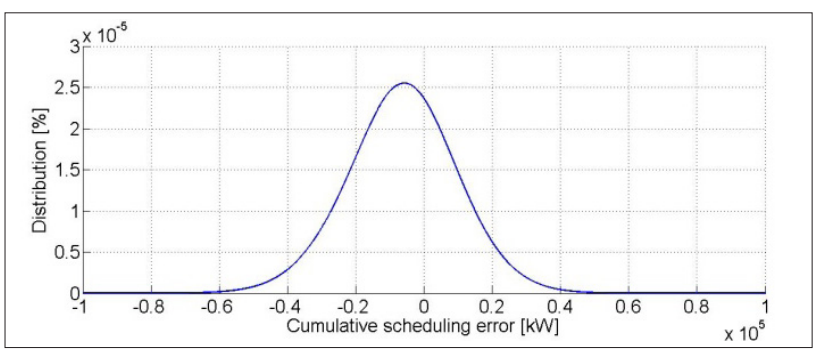

Fig. 2 Distribution of the cumulative scheduling error of the examined wind power plants

It can be seen, that even the use of such simple method, as described in this section, may give a more detailed view on the issue of the determination of balancing reserves.

\subsection{Redesigned system to decrease the amount of balancing reserves}

The aim of the research is to create an accurate planning method, while trying to involve the wind power plants in the process by using financial motivation. To fulfil this, the author proposes changes of the current system, which changes affect the obligatory electricity purchase system and the tariff structure.

\subsubsection{New scheduling and obligatory electricity purchase system}

Hungarian wind power plant operators have been criticizing the obligatory electricity purchase system since its introduction, mainly because of the regulations concerning scheduling. This issue was evaluated multiple times by the author over the years [18-24], however only minor changes were made by the regulator.

The first proposal of the author is to categorise wind power plants based on their nameplate capacity, thus different expectations can be applied for single turbines and wind farms of given capacities. The required accuracy of production schedules, presented by operators, would be determined based on the average of the historical accuracy of units in the same category

The second proposed change is to cease the current tariff structure that is based on feed-in and penalty tariffs, and to introduce a new system, based on "base" and "bonus" (hereinafter Base and Bonus) elements. In this way the current rewarding-penalizing structure would be replaced by a purely rewarding system. It would also help to apply new EU regulations and to resolve the contradiction between different settlement procedures; while penalties are calculated based on daily settlement volumes, the reserve market is operated on a quarter-hour basis. In the proposed system, RMS error of the schedule of wind power plants would be calculated in every quarter-hour.
If this error exceeds the expected accuracy of the category, no bonus is paid for the operator. If the RMS error is within the limits, the market price (Base) is topped with a pre-determined tariff (Bonus).

$$
\begin{aligned}
& I F P_{\text {error }_{i}} \leq R M S E_{\text {category }_{i}} \rightarrow p=\text { Base }+ \text { Bonus }\left(R M S E_{\text {actual }_{i}}\right) \\
& I F P_{\text {error }_{i}}>R M S E_{\text {category }_{i}} \rightarrow p=\text { Base }
\end{aligned}
$$

After introducing the quantities of total energy sold, when inside and outside the expected error range $\left(E_{\text {inside }}\right.$ and $\left.E_{\text {outside }}\right)$, total revenue of a power plant can be calculated as:

$$
R_{i}=E_{\text {inside }} \cdot\left(\text { Base }+ \text { Bonus }\left(R M S E_{\text {category }}\right)\right)+E_{\text {outside }} \cdot \text { Base }
$$

\subsubsection{Choosing Base and Bonus tariffs}

In order to properly determine Base and Bonus tariffs, regulations summarized at the end of Section 1 have to be taken into consideration. If wind power plants had to sell their electricity on the market, they would have received an annual average price of $12 \mathrm{HUF} / \mathrm{kWh}$ (40 EUR/MWh), based on the data of HUPX Hungarian Power Exchange Company Ltd. This is set as the Base tariff of the system. Since the additional financial support must not exceed the difference between lifecycle costs and market prices, these latter two determine the upper boundary of the Bonus tariff as well. According to recent studies of Fraunhofer, levelized cost of electricity for wind power plants, operating 2000 hours a year are approximately 70 EUR/MWh. [25] Based on this, Bonus tariff cannot exceed approximately $30 \mathrm{EUR} / \mathrm{MWh}$, thus this value was selected as the average amount of this tariff element.

\subsubsection{Formulation of the multiplier of Bonus tariff}

The last element of the proposal is the determination of the RMS error dependent multiplier of the Bonus tariff, shown in (3). The aim of the resulting Bonus $\left(R M S E_{\text {category }}\right)$ function is primarily to distinguish wind farms from each other, based on the accuracy of their schedule.

Multiplier of the Bonus tariff is determined using the amount of control reserve, required by the wind farms, plotted against their RMS error. In general, the higher the RMS error, the bigger the necessary reserve, thus correlation between the multiplier of the Bonus tariff and the RMS error should be negative. The resulting linear approximation function should pick up the value 1 at the average RMS of the category. These are shown on Fig. 3.

\subsubsection{Planning the amount of balancing reserves}

Due to the structure of the proposed tariff system, it can be ensured that financial coverage is available in case scheduling error of wind power plants exceeds their average uncertainty level. The most important difference between the proposed method and the other conventional ways of planning the 
reserves is the $p d f$, which is used as the input of the method. Since by definition a $p d f$ has to fulfil (4), if parts of the func-

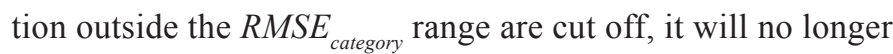
be a $p d f$.

$$
\int_{-\infty}^{+\infty} f\left(P_{\text {error }}\right) d P_{\text {error }}=1
$$

The solution is to rescale the truncated function, according to $(5)$.

$$
\mathrm{f}^{\prime}\left(\mathrm{P}_{\text {error }_{\mathrm{i}}}\right)=\mathrm{f}\left(\mathrm{P}_{\text {error }_{\mathrm{i}}}\right) /\left(\int_{-\mathrm{RMSE}_{\text {category }}}^{+\mathrm{RMSE}_{\text {categry }}} \mathrm{f}\left(\mathrm{P}_{\text {error }_{\mathrm{i}}}\right) \mathrm{dP}_{\text {error }_{\mathrm{i}}}\right)
$$

These rescaled functions are to be convolved, to calculate balancing reserve needs, which are expected to be significantly smaller compared to conventional methods.

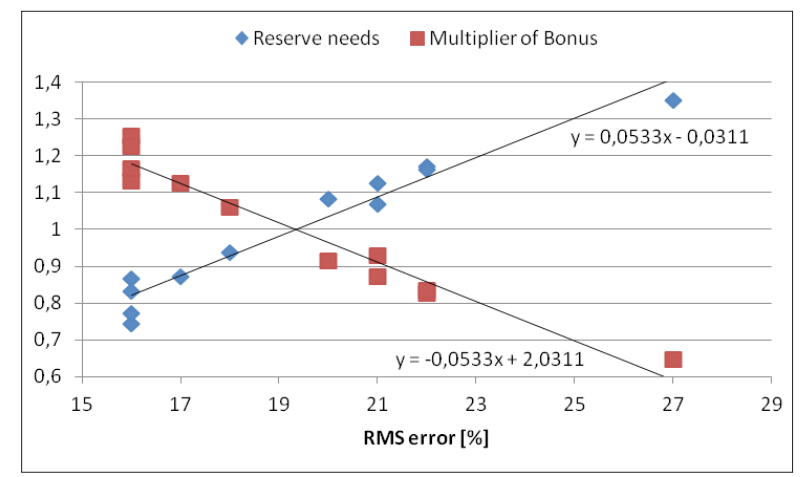

Fig. 3 Control reserve needs of individual wind power plants, and the resulting multiplier of Bonus tariff for the examined category, plotted against the RMS error

\section{Results}

Wind power operators usually handle schedules as confidential data, thus demonstration of the different tariff structures is rather hard. The author has used and 8-month long dataset, provided by a Hungarian wind farm, with a total capacity of $24 \mathrm{MW}$. This dataset was divided to four parts. As the operator has purchased power forecasts from three different companies, by pairing these with the actual production values, a total of twelve wind farms could be demonstrated.

RMS error of these fictive wind farms varies between 16 and $27 \%$, with the average of 19.33 , which means that during a significant part of the operation, the units are penalized due to their scheduling error. Using the above introduced average feed-in tariff and the penalty tariff, total and energy specific revenue of the twelve wind farms was calculated. The latter was in the range of 30.28 and $30.97 \mathrm{HUF} / \mathrm{kWh}$ (100.9 and 103.2 EUR/MWh). The correlation between the RMS error of the wind farms and their energy specific revenue was 0.719 . Fig. 4 shows these energy specific revenues normalized to the average of the group.

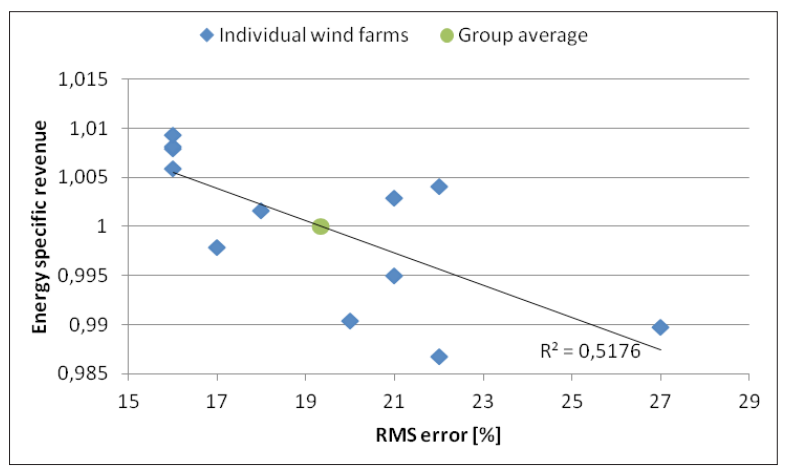

Fig. 4 Energy specific revenue of wind farms according to current legislations, plotted against the RMS error of their schedule; current tariff system

The $p d f$ of these scheduling errors can also used to determine the amount of control reserves necessary for different confidence levels, as shown previously. During the examinations, necessary reserves were calculated for 50, 90, 95 and 99\% confidence level for all twelve plants, and it was also examined how the situation changes if the total portfolio is acting as a single balancing group. If reserve needs are normalised to the nominal power of the wind farms, $7-10 \%, 26-47 \%, 34-63 \%$ and $50-91 \%$ reserve must be kept in the system in case of 50 , 90, 95 and 99\% confidence levels, respectively. In contrast, if the twelve units are considered as a single balancing group, the volume of reserves reached only $4,10,12$ and $16 \%$, respectively. The dependence on confidence level is shown on Fig. 5, while the accuracy of the schedule is illustrated by Fig. 6.

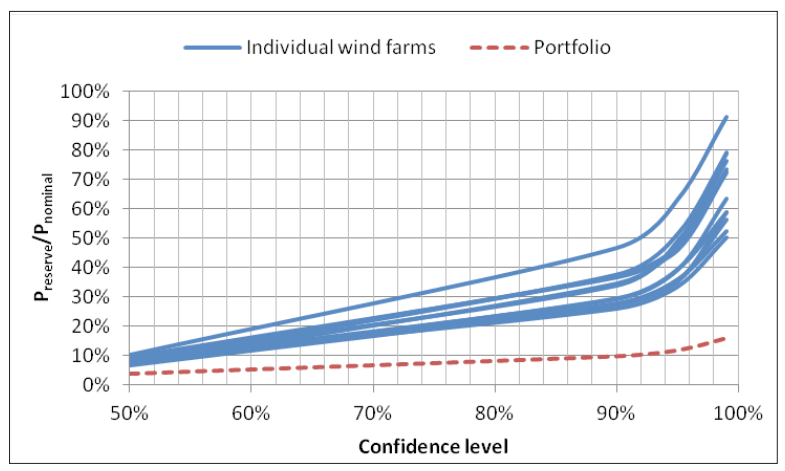

Fig. 5 Amount of required reserve plotted against different confidence levels

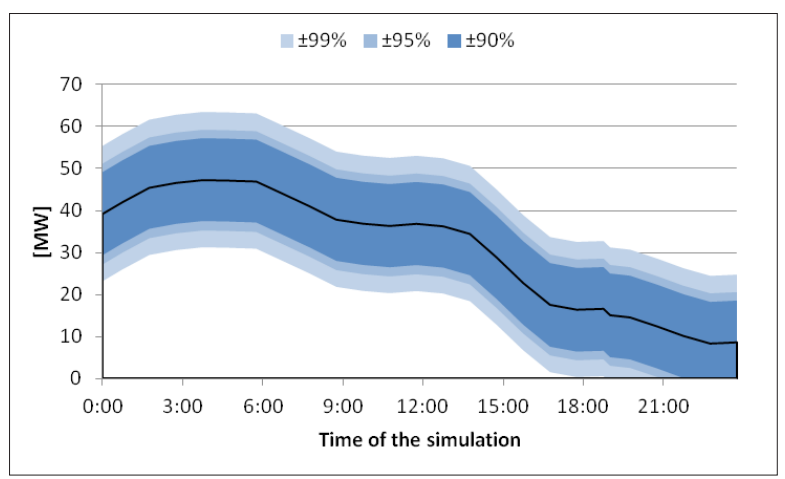

Fig. 6 The schedule presented by the examined wind power plants and different uncertainty levels according to the current system 
Using the proposed system, detailed in Section III., total and energy specific revenue of the twelve wind farms was calculated again. The latter is in the range of 14.95 and $19.36 \mathrm{HUF} / \mathrm{kWh}$ (49.8 and 64.5 EUR/MWh), which values are both below the upper boundary calculated according to legislations. The correlation between the RMS error of the wind farms and their energy specific revenue was improved from 0.719 to 0.975 : this is shown on Fig. 7.

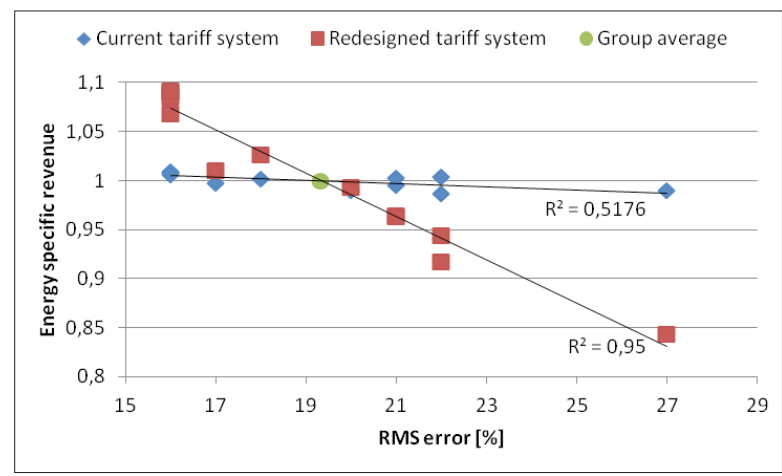

Fig. 7 Energy specific revenue of wind farms, plotted against the RMS error of their schedule; current and new tariff system

The proposed system is also able to decrease the amount of control reserves in the system.

Necessary reserves were calculated for 50, 90, 95 and $99 \%$ confidence level for all twelve plants, and the total portfolio. If reserve needs are normalised to the nominal power of the wind farms, $4-5 \%, 12-20 \%, 14-24 \%$ and $15-26 \%$ reserve must be kept in the system in case of 50, 90, 95 and 99\% confidence levels, respectively. If the twelve units are considered as a single balancing group, the volume of reserves reached only 2, 5, 6 and $7 \%$, respectively. These results are shown on Fig. 8.

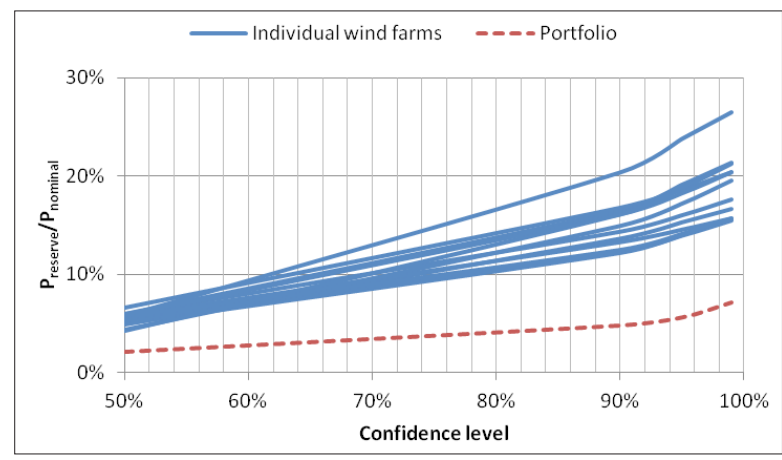

Fig. 8 Amount of required reserve plotted against different confidence levels

On Fig. 9 a direct comparison of the current and the redesigned system is shown. On average, reserve requirements are decreased by $2.77 \%, 17.93 \%, 26.66 \%$ and $48.7 \%$ for $50,90,95$ and $99 \%$ confidence levels, respectively. This decrease is significantly smaller in case of the whole portfolio: $1.9 \%, 5.16 \%$, $6.38 \%$ and $8.97 \%$, respectively, which are still valuable decrements. The effect of this decrease is illustrated by Fig. 10.

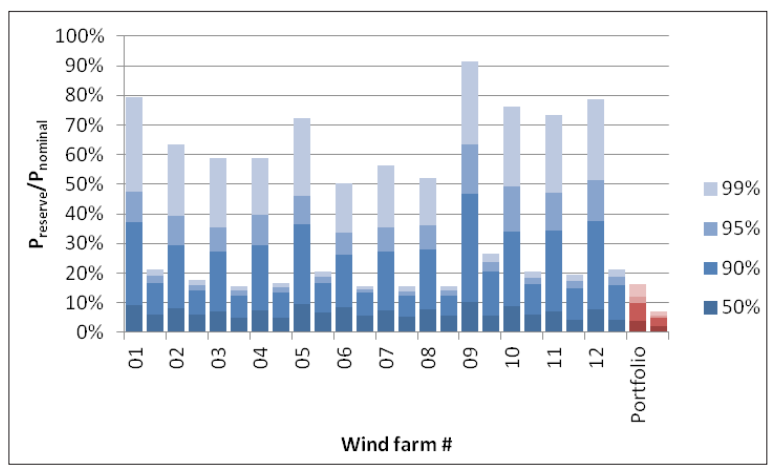

Fig. 9 Amount of required reserves in case of the current and the redesigned system, for different confidence levels

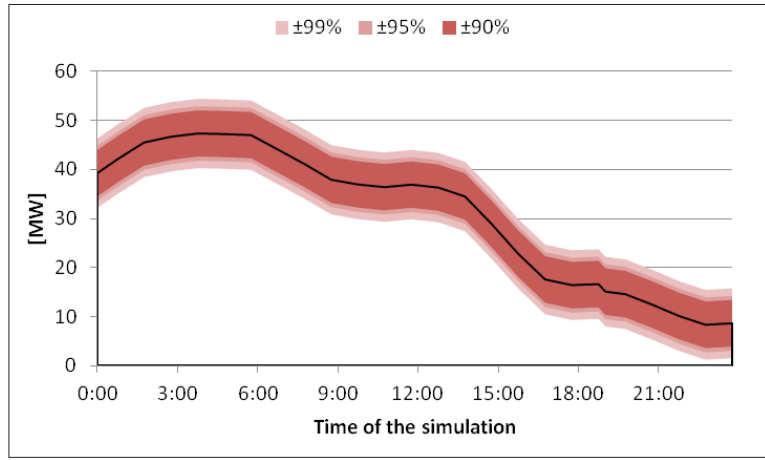

Fig. 10 The schedule presented by the examined wind power plants and different uncertainty levels according to the redesigned system

The proposed new method is not only affecting the amount of necessary control reserves, but also the nature of the distribution of the errors. As it can be noticed on Fig. 11, the shape of the $p d f$ is much thinner, and also the median is shifted slightly. It is also highlighted that actual control reserves in the system must be asymmetrical for the examined dataset, since all producers are overestimating their production. However, since the Hungarian power system usually has more upwards than downwards reserve available, such bias of the $p d f$ can be handled rather easily.

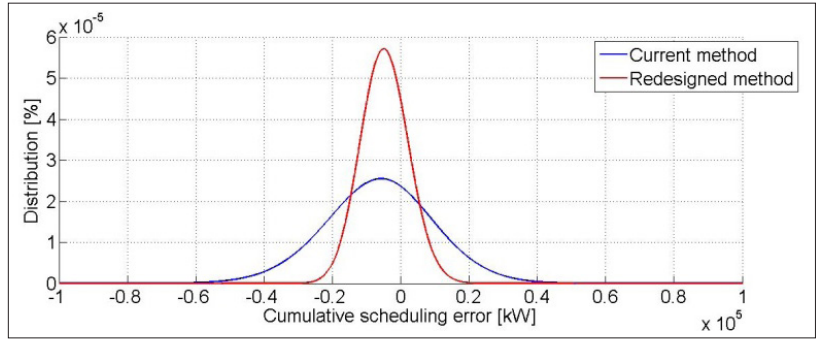

Fig. 11 Distribution of the cumulative scheduling error of the examined wind power plants, used to determine the amount of reserves, according to the current and the redesigned system 


\section{Conclusions}

Examination performed by using actual schedule and production data has shown that the proposed tariff system could motivate wind power plant operators to decrease their uncertainty range as much as possible and in case they exceed this range, by not receiving the Bonus tariff, financial assets are available to cover the cost of the use of unplanned control reserves. The two effects jointly allow the transmission system operator to utilise less control reserve by taking into consideration the scheduling error of wind power plants, while also applying new European directives.

The method presented in this paper can be applied to other intermittent renewable energy sources, in particular for solar photovoltaics. Future work aims to examine these options as well as extending the input dataset.

\section{References}

[1] IEA Wind Task 25, "Design and operation of power systems with large amounts of wind power." 2009.

[2] Holttinen, H., Milligan, M., Ela, E., Menemenlis, N., O’Malley, M., Flynn, D., Rawn, B., Gomez, E., Dobschinski, J. "Reserve requirements of wind power." In: Proceedings of the EWEA Annual Event, Brussels, Belgium, March 16, 2011.

[3] Dobschinski, J., Lange, B., Rohrig, K., Saint-Drenan, Y., Wessel, A., von Bremen, L. "The Potential of Advanced Shortest-Term Forecasts and Dynamic Prediction Intervals for Reducing the Wind Power Induced Reserve Requirements." In: Proceeding of the European Wind Energy Conference \& Exhibition, Warsaw, Poland, April 20-23, 2010.

[4] Hasche, B., Barth, R., Swider, D. J. "Effects of improved wind forecasts on operational costs in the German electricity system." In: Energy and Environmental Modeling 2007

[5] European Wind Energy Association, "Electrical Grids and wind power the present situation in Europe." 2005

[6] European Wind Energy Association, "Balancing Responsibility and Costs of Wind Power Plants." 2015.

[7] Liu, B., Zhou, J., Pan, Y., Li, Q., Zhou, H., Ding, Q. "Review of Generation Schedule Methods with Large-Scale Wind Power Integration." In: 2011 Asia-Pacific Power and Energy Engineering Conference, Wuhan, March 25-28, 2011, pp. 1-4.

https://doi.org/10.1109/APPEEC.2011.5748415

[8] Zhang, Y., Zhou, M., Li, G. "Wind Power Price Regulation Considering Wind Power Fluctuation." In: 2010 5th International Conference on Critical Infrastructure (CRIS), Beijing, Sept. 20-22, 2010, pp. 1-4. https://doi.org/10.1109/CRIS.2010.5617571

[9] Ávila, J. P. C., Hakvoort, R. A., Ramos, A. "Short-term Strategies for Dutch Wind Power Producers to Reduce Imbalance Costs." Energy Policy. 52, pp. 573-582. 2013. https://doi.org/10.1016/j.enpol.2012.10.011

[10] Holttinen, H., Saarikivi, P., Repo, S., Ikäheimo, J., Koreneff, G. "Prediction Errors and Balancing Costs for Wind Power Production in Finland." In: Proceedings of the Global Wind Power Conference, Adelaide, Australia, Sept. 18-21, 2006, pp. 1-11.
[11] Uchida, Y., Tindal, A., Parkes, J., Munoz, L. "Wind Energy Trading Benefits Through Short Term Forecasting." Proceedings of Japan Wind Energy Symposium. 30, pp. 155-158. 2008. https://doi.org/10.11333/jweasympo1979.30.155

[12] McKeogh, E., Ó Gallachóir, B., Lang, S., McCarthy, J., Murray, P., Jørgensen, J., Möhrlen, C. "Wind Energy Forecasting of the Irish Power System using a Multi-Scheme Ensemble Prediction System." In: SEI Forum, April 27, 2007.

[13] Lange, B., Rohrig, K., Ernst, B., Schlögl, F., Cali, Ü., Jursa, R., Moradi, J. "Wind power prediction in Germany - Recent advances and future challenges." In: Proceedings of the European Wind Energy Conference \& Exhibition, Athens, Greece, 2006, Paper \#745

[14] Wessel, A., Dobschinski, J., Lange, B. "Wind Power Prediction for Power System Operation." In: Proceedings of the GTZ-TERNA Expert Workshop, Berlin, Germany, 2009.

[15] Hungarian Energy Office, "A magyar villamosenergia-rendszerbe illeszthető szélerőművek mennyisége." (The maximal amount of wind capacity to be installed in the Hungarian Power System.), 2009. (in Hungarian)

[16] European Commission, "Guidelines on State aid for environmental protection and energy 2014-2020, (2014/C 200/01)." 2014.

[17] ENTSO-E, "Continental Europe Operation Handbook - Policy 1, LoadFrequency Control and Performance." 2009.

[18] Hartmann, B., Csetvei, Zs. "Support Policies Regarding Wind Generation, and Use of Storage Technologies from the Viewpoint of the TSO." In: Proc. 9th International Conference on Heat Engines and Environmental Protection, Balatonfüred, Hungary, 2009, Paper \#3

[19] Hartmann, B., Csetvei, Zs., Dán, A. "The Scheduling Methods of Wind Generator Production, and Use of Storage Technologies to Avoid Penalty Tariffs." In: Proceedings of the 2nd International Youth Conference on Energetics 2009 (IYCE 2009), Budapest, Hungary, 2009, Paper \#415

[20] Hartmann, B. "Keeping preliminary scheduled wind power generation by means of energy storage." In: Proceedings of the 10th Jubilee International Conference on Heat Engines and Environmental Protection, Balatonfüred, Hungary, 2011, Paper \#19

[21] Hartmann, B., Dán, A. "Wind Power Prediction, System Regulation Cost and CO2 Emission as Function of Energy Storage - Simulation Tool for Problem Solving." In: 2011 IEEE Trondheim PowerTech, Trondheim, June 19-23, 2011, pp. 1-7. https://doi.org/10.1109/PTC.2011.6019362

[22] Hartmann, B., Dán, A. "Energy Storage - Tool for Decreasing the Error of Wind Power Forecast." In: Proceedings of the 2011 3rd International Youth Conference on Energetics (IYCE), Leiria, Portugal, July 7-9, 2011, pp. 1-8.

[23] Hartmann, B., Dán, A. "Energy Storage as Function of the Tariff System - Is it the Solution." Electrotehnica Electronica Automatica. 2, pp. 2735. 2011.

[24] Hartmann, B., Dán, A. " Szélerőművi termelés menetrendi hibájának csökkentése energiatárolóval - van-e kellö motiváció?" (Decreasing the Forecast Error of Wind Power Production by Mean of Energy Storage Is there Sufficient Motivation?) Energiagazdálkodás. 4, pp. 7-10. 2011. (in Hungarian)

[25] Fraunhofer ISE, "Levelized Cost of Electricity - Renewable Energy Technologies." 2013. 